\title{
O TEXTO IMAGÉTICO NA CONSTRUÇÃO DA AUTORIA
}

\author{
Carolina FERNANDES \\ Carla Carolina de Vargas OLIVEIRA \\ (Universidade Federal do Pampa) \\ carolinafernandes@unipampa.edu.br
}

RESUMO: O presente artigo, desenvolvido sob o apoio teórico da Análise do Discurso, se propõe a apresentar um estudo acerca do uso de textos imagéticos nas aulas de Língua Portuguesa como facilitador da assunção dos alunos à autoria de seus textos. Segundo os Parâmetros Curriculares Nacionais (BRASIL,1997), o texto assume um papel importante no ensino de Língua Portuguesa. Porém, é explorado de modo a não contribuir com a capacidade interpretativa dos alunos, ou seja, utilizado para o ensino de metalinguagem. Dessa maneira, a escola forma alunos dependentes do discurso pedagógico, que somente reproduzem o imposto pela escola; são os denominados sujeitos-escreventes (ASSOLINI, 2008). Já os sujeitos-autores são aqueles que dotam seus textos de sentidos (ORLANDI, 2002), conforme sua constituição ideológica. Com o objetivo de analisar os gestos interpretativos e a posição dos alunos quanto à autoria na leitura do texto imagético, a coleta dos dados foi aplicada em uma $7^{\underline{a}}$ série de uma escola do Ensino Fundamental. Para isso, propomos uma produção textual a partir da leitura de um texto imagético e após, houve a reescritura imagética deste. Através das análises, percebemos que, em muitos momentos de suas escrituras, os alunos criaram o efeito de originalidade, logo o interpretaram singularmente. Nas reescrituras imagéticas, por sua vez, eles deslocaram os sentidos postos pelo texto-origem, preenchendo as lacunas deixadas pela imagem. Assim, foi possível concluir que o uso de textos imagéticos, nas aulas de Língua Portuguesa, estimula os alunos a assumirem a autoria de seus textos.

Palavras-chave: Texto Imagético. Leitura/Escrita Imagética. Aluno-Autor.

\section{THE IMAGE TEXT AND THE CONSTRUCTION OF AUTHORSHIP}

ABSTRACT: This article, developed with the theoretical support of discourse analysis, proposes to present a study about the use of pictorial texts in Portuguese classes to help the students develop their sense of authorship texts. According to the National Curriculum Parameters [PCN] (BRASIL. 1997), the text plays an important role in teaching Portuguese. However, it does not contribute to the interpretative skills of the students, that is, it is not used for meta-language teaching. Thus, the school makes students dependent on pedagogical discourse, who end up only reproducing what the school imposes; 
these are the writing-subjects (Assolini, 2008). The author-subjects are those who endow meaning to the texts (ORLANDI, 2002), according to their ideological constitution. In order to analyze the interpretative gestures and the position of the students as to the authorship when reading the pictorial text, data was collected in a 7th grade class at an elementary school. Thus we proposed a text production activity based on the reading of a pictorial text. After that, there was the pictorial rewriting of this. The analysis revealed that, through their writing, the students created the effect of originality, thus interpreting the text in a unique way. In the pictorial rewriting they shifted the meaning given by the source-text, filling the gaps left by the image. Thus, it was concluded that the use of pictorial texts, in Portuguese classes, encourages students to develop their sense of authorship.

Keywords: Pictorial Text. Pictorial Reading/Writing. Student-Author.

\section{Considerações iniciais}

O presente artigo tem por finalidade apresentar uma investigação acerca do uso do texto imagético, nas aulas de Língua Portuguesa do Ensino Fundamental, como facilitador da assunção dos alunos à autoria de seus textos. A coleta dos dados se concretizou através da proposta da escrita de um texto verbal e reescritura imagética a partir da leitura da sequência de imagens Pega Ladrão, retirada da obra A Bruxinha Atrapalhada, de Eva Furnari (1984). Estas análises se realizam sob a perspectiva teórica da Análise do Discurso de linha francesa. Os dados que embasam esta pesquisa foram coletados em uma $7^{\underline{a}}$ série da Escola Estadual de Ensino Fundamental Coronel Urbano das Chagas, situada na cidade de Dom Pedrito.

No que tange à tradição do ensino de Língua Portuguesa, prima-se pela formação de sujeitos capazes de ler e escrever. A leitura, normalmente através de extensos textos verbais, serve para a aprendizagem da metalinguagem, vocabulário e descoberta de uma única mensagem presente nestes, a do autor. A escrita, por sua vez, propicia o uso e a memorização das regras gramaticais. Motivado por essa prática, o que o sistema escolar conseguiu promover foi a formação de meros reprodutores do discurso pedagógico. Diante dessa problemática questão, houve o aprofundamento de estudos e pesquisas acerca das aulas de Língua Portuguesa, passando a investigar o desenvolvimento de 
habilidades que ultrapassem o simples ato de ler e de escrever, pela formação de cidadãos que refletem e se expressam na sociedade. $E$ isso somente se faz possível quando os alunos se desprendem da posição de meros escreventes e produzem um efeito de singularidade em seus textos.

O aluno na posição de autor é aquele capaz da autoria do seu próprio texto, usa-o como forma de expressão, ou seja, cria o efeito de singularidade. O aluno escrevente, por sua vez, é aquele que simplesmente reproduz as regras gramaticais e transmite, para seu texto, o discurso pedagógico fornecido pelo sistema escolar (CORACINI, 2010). O primeiro se apropria da sua produção escrita e o marca com sua singularidade enquanto sujeito, já o segundo, se torna um receptor e reprodutor das exigências feitas nas aulas de Língua Portuguesa.

Faz-se importante destacar que não somente o verbal é texto, mas todas as diferentes formulações significantes (LAGAZZI, 2010 p.83) também o são. Por isso, se ressalta a importância da escola oferecer aos alunos diversas materialidades do discurso, dentre elas, a imagem, considerando-a por sua opacidade, que induz ao aluno uma pluralidade de interpretações. A imagem é materialidade histórica e social, por isso é opaca e permite essa variedade de interpretações.

Este artigo está dividido em três partes. A primeira aborda o texto, enquanto objeto de análise, em suas possíveis materialidades. A segunda parte, por sua vez, trata do sujeito ideológico e histórico, frente ao texto, enquanto autor ou mero escrevente. Na terceira parte, será ressaltada a importância da reescritura no processo de assunção à autoria pelo aluno, já que através da leitura de um textoorigem, o aluno, por meio de gestos interpretativos se afasta do discurso do autor, dotando-o de sentido. Em todos os capítulos, a teoria estará articulada às análises, de modo a construir um dispositivo teórico-analítico próprio à pesquisa.

\section{O texto imagético e a pluralidade de leituras}

O uso do texto nas aulas de Língua Portuguesa é imprescindível, já que este, se explorado adequadamente, contribui com o desenvolvimento das capacidades interpretativas dos alunos. Segundo Orlandi (Apud FERNANDES, 
2012, p. 128), o texto é um espaço de significação, sendo assim, tudo a partir do qual se pode criar um efeito de sentido e se tem a possibilidade de interpretar, é texto. Com isso, o texto pode se apresentar em diversas materialidades. Uma imagem, um gesto, um som são interpretáveis e possuem algo em comum, o de provocar, de instigar alguém a interpretá-los. E, a escola deve oferecer aos seus alunos esta pluralidade de materialidades textuais para que sirvam de estímulo à interpretação dos alunos.

O texto tem por finalidade materializar o discurso, esse último, de acordo com Pêcheux (1969, apud ORLANDI, 2012, p. 137), é um efeito de sentido entre interlocutores. Nessa produção de efeito de sentido, possível nos textos, é que autor e leitor se encontram. O texto, apesar de ser produzido por um autor, não é homogêneo e nem possui um sentido predeterminado, pelo contrário, é no cruzamento da constituição discursiva, de autor e leitor, que esse sentido é produzido.

Segundo os documentos oficiais é dever da escola propiciar aos alunos os recursos tecnológicos, entre eles o livro, visto que este vem evoluindo conforme o tempo e já trazem novas formas de escrita, como propõem Martins (1957) e Chartier (2009), sendo um exemplo o livro de imagens analisado por Fernandes (2012). Principalmente pela opacidade de sua materialidade, um mesmo texto imagético pode provocar diferentes efeitos de sentido entre os leitores, já que cada leitor possui sua história de leitura. A pluralidade de interpretações, advindas das leituras de imagens, proporciona aos alunos a autonomia, a liberdade nas suas leituras, pois, como já dito, elas são opacas, consequentemente facilitam a assunção do sujeito à posição de autor.

Ambas as práticas do ensino de Língua Portuguesa, a leitura e a escrita, servem para que os alunos aprendam a manipular a linguagem. A leitura, para a escola, é a decodificação da materialidade do texto, ou seja, é possível interpretar o que está visível, encontrar a literalidade do texto. Como se esse sentido estivesse acabado nele. Pelo contrário, a leitura é o caminho material pela qual se alcança à interpretação (LEANDRO-FERREIRA, 2005). Assim, entendemos que os gestos de leitura vão além da significação da materialidade textual, o sentido é produzido na opacidade do texto, dependente da ideologia e historicidade de quem lê. A interpretação requer produção de sentidos. 
É importante salientar que, mesmo havendo uma pluralidade de leituras para um mesmo texto, não é qualquer leitura que é válida. Orlandi (1996) alerta que há leituras possíveis para um texto, mas não qualquer leitura. Logo, as leituras adequadas para um mesmo texto devem estar relacionadas com sua materialidade. Através da leitura verbal e reescritura imagética da sequência de imagens Pega Ladrão do livro de imagens A Bruxinha Atrapalhada, de Eva Furnari (2008), foi possível perceber o gesto singular de leitura, por exemplo, no modo como os alunos organizaram o desfecho da história, como direcionaram alguns elementos das narrativas, como preencheram outros, indicando motivações para as ações e designando os personagens.

É encargo das escolas o oferecimento de novas formas de aprendizagem da leitura e da escrita aos alunos, em que eles interajam ativamente nesse processo de construção do conhecimento, e não se tornem meros receptores de regras gramaticais. Afinal cidadãos que estão inseridos na sociedade não se comunicam através de textos corretos gramaticalmente e vazios de significação, já que a interpretação e a produção de sentidos são indispensáveis à constituição subjetiva e à assunção do sujeito à posição-autor.

\section{Aluno-autor versus Aluno-escrevente}

O homem adquire significação na história através da linguagem, pois como defende Orlandi (2008), é através dela que ele se constitui como sujeito do discurso. O sujeito se constitui concomitantemente ao sentido, logo por meio de gestos de interpretação ocupa sua posição na sociedade. Segundo LeandroFerreira (2005, p. 21), o sujeito é o resultado da relação com a linguagem e a história. Sendo assim, pode-se entender que este é determinado por fatores internos e externos, o primeiro quando se refere à ideologia, ou melhor, às formações discursivas em que o sujeito se insere, e o segundo, por sua vez, quando se faz menção à história.

O sujeito, que está inserido na sociedade, é constantemente afetado por formações ideológicas. Tais formações se materializam nas denominadas formações discursivas (FD). E, conforme o sujeito se desenvolve ideologicamente sua formação discursiva se configura (ORLANDI, 2002, p. 44), trata-se de um 
processo contínuo. Como defende Orlandi (2002, p.43) com base em Pêcheux, a formação discursiva se define como aquilo que numa formação ideológica dada ou seja, a partir de uma posição dada em uma conjuntura sócio-histórica dadadetermina o que pode e deve ser dito.

Assim, entende-se que o discurso é efeito de sentidos, já que a fala do sujeito se inscreve em uma formação discursiva. É através dela que podemos compreender os diferentes sentidos para uma mesma palavra ou imagem. Durante a produção textual dos alunos a partir do texto imagético, foi possível constatar a circulação de um discurso produzido pela sociedade com o efeito de um estereótipo acerca da figura do "ladrão", como percebemos nas sequências discursivas (SD) retiradas dos textos dos alunos produzidos a partir da narrativa visual SD-1 e SD-2:

\section{SD-1}

Quando ele caiu, a bruxinha deu um grande sermão nele, dizendo que ele nunca deve roubar nada de nenhum lugar ou de ninguém.// [...] Quando o ladrão tirou o disfarce, a bruxinha Matilde se espantou, pois era uma simples garotinha.

SD-2

Quando Isabel acordou, imediatamente, o homem já ia no meio da rua com Frederico no colo. A bruxinha, rapidamente, pegou sua varinha e jogou um feitiço no ladrão para que uma pedra aparecesse em seu caminho e ele caísse no chão. E não é que ele caiu? Na mesma hora, ela deu uma bronca no homem da capa preta. // [...] Mas descobriu que não era um homem. Quando ele tirou o chapéu e os óculos, era apenas uma mocinha, que disse que sempre quis um gato igual a Frederico.

Em ambas as SDs, percebemos que há uma formação discursiva que relaciona a figura do ladrão ao gênero masculino e à maior idade, como se não houvesse a possibilidade de uma ladra (gênero feminino). A SD-2 ainda invalida a periculosidade de uma ladra jovem, dizendo: era apenas uma mocinha; mesmo que as pessoas, em geral, estejam sempre em contato com as notícias criminais, onde se veem jovens mulheres no mundo do crime. 
A importância da leitura do texto imagético em sala de aula é justamente o de fazer com que o aluno produza o efeito de singularidade, que se faz possível quando ele está exposto à opacidade da imagem, preenche as lacunas deixadas por ela e interpreta conforme sua formação discursiva. Outra posição adotada pelos sujeitos-alunos foi o motivo pelo qual o ladrão queria roubar o gato. Este fugiu do discurso convencional da sociedade nas duas sequências discursivas que vemos a seguir:

\section{SD-3}

Mas o que a bruxa não esperava é que o ladrão fosse uma menina, que queria pegar o gatinho de estimação dela, porque o seu havia desaparecido e era muito parecido com o gato da bruxa.

Esse gesto de interpretação, concebido na SD, foge ao discurso do sensocomum sobre o roubo. Pois o roubo está relacionado a um discurso moralizante imposto pelo cristianismo e reforçado pelo jurídico. Esse discurso que descrimina 0 ato do roubo explica o modo como os gestos interpretativos inocentam esse fato narrado na sequência de imagens apresentada. Logo, é possível entender que o aluno interpretou e se posicionou como autor através da produção do efeito de originalidade.

De acordo com a perspectiva da Análise do Discurso, sabemos que um texto ganhará sentido no momento da leitura. Com isso, percebe-se que há a descentralização do autor como produtor de sentido do texto. Esse fato é denominado por Foucault (apud Lagazzi, 2010) como morte do autor, que acontece quando não se faz a referência ao indivíduo empírico do autor. Mas em um texto não é possível anular toda e qualquer ação do autor, sua função, dentro do texto, é imprescindível. Como explica o mesmo teórico (ibidem), o autor é o princípio do agrupamento do discurso. Logo, um texto não existirá se não possuir uma organização da dispersão discursiva.

Quando o sujeito escreve, visual ou verbalmente, ou lê, ele está interpretando. Ele tem a necessidade de dar sentido ao texto, pois o sujeito está exposto à opacidade do texto, como defende Pechêux (1990 apud Orlandi, 1996), já que este não é transparente. A interpretação se faz possível quando o sujeito 
usa o já-dito, e atribui sentido de acordo com sua formação discursiva. Logo, ao interpretar, o sujeito se apropria do intradiscurso (LEANDRO-FERREIRA, 2005) para expor o já-dito, que se encontra no interdiscurso. Nesse movimento de dotar de subjetividade o já-dito, ele assume a posição de autor. Assim, se assume como produtor de linguagem, de acordo com Orlandi (2012, p.103).

O aluno na posição de autor é aquele que cria um efeito de singularidade em seu texto e se apropria dele para se constituir como sujeito inserido na sociedade. O trabalho equivocado com o texto, aquele que usa o texto para se explorar a metalinguagem, faz com que se crie um discurso pedagógico que tolhe a capacidade do sujeito de se posicionar como autor, como produtor de sentidos, e de se apropriar de um gesto interpretativo singular. Assim, o que ocorre é que o aluno é incitado a reproduzir, inconscientemente, o discurso adquirido na própria escola (CORACINI, 2010). E, desse modo, surgem os denominados sujeitosescreventes (ASSOLINI, 2008), aqueles que não conseguem deslocar-se da posição de sujeito enunciador de discursos estabilizados (ibidem, p.98). Na sequência discursiva abaixo, percebemos um aluno que tenta se colocar na posição de escrevente:

\section{SD-4}

Era uma vez uma bruxinha que estava dormindo com seu gatinho e um ladrão apareceu e roubou o gatinho. Daí, a bruxinha acordou e seguiu o ladrão, usou uma varinha mágica e fez aparecer uma pedra no caminho do ladrão. Ele tropeçou e era uma bruxa que queria o gatinho porque sempre quis ter um. Daí a outra bruxa fez um feitiço e apareceu um gatinho e viveram todos felizes para sempre.

Em poucas linhas, o aluno discorre sua interpretação sobre a sequência de imagens e produz o efeito narrativo. Diferente das demais produções dos alunos, ele não produziu, totalmente, o efeito de singularidade como os outros. Porém, cabe salientar que embora esse aluno tenha tentado se colocar na posição de escrevente, ele ainda assim foi exposto à opacidade da imagem e levado, ou ainda, induzido a preencher as lacunas desse texto, como faz em: Ele tropeçou e era uma bruxa que queria o gatinho porque sempre quis ter um. Nesse período, 
encontramos duas produções de sentido advindas da autoria do texto. A primeira se refere ao segundo personagem designado por "bruxa" no texto, este seria quem queria se apoderar do gatinho. Pelas demais leituras analisadas e pelo texto-origem, vimos que não se trata de uma personagem bruxa e sim de uma jovem. Também não podemos deixar de mencionar que, no mesmo período, encontramos a motivação do roubo do personagem: sua constante vontade de possuir tal animal. Como percebemos, a opacidade do texto imagético induz o aluno a assumir-se na posição de autoria.

Juntamente com as formações discursivas, há outro fator determinante na interpretação dos sujeitos, que são as denominadas histórias de leituras. A exposição do sujeito às cantigas, às imagens, aos filmes, aos livros infantis, obras literárias, faz com que o sujeito construa uma espécie de arquivo de leituras, onde guarda tudo que the proporcionou um efeito de sentido e, ao longo da ampliação desse arquivo, não lerá um texto da mesma maneira que antes. Durante as análises das produções textuais dos alunos que participaram da presente pesquisa, foi perceptível a presença de textos anteriores que compõem as suas histórias de leitura, como percebemos na SD abaixo:

\section{SD-5}

Era uma vez uma bruxa que não era tão bruxa assim, seu nome era Ofélia, ela era muito bondosa. Ofélia estava em seu castelo, dormindo tranquilamente com o seu gatinho chamado Lauro, quando de repente ouviu alguns sons que vinham em sua direção. //[...] E Marta viveu feliz para sempre com seu novo gatinho e Ofélia com seu gato Lauro, também.

Esse texto foi escolhido por dois motivos. O primeiro é a referência que 0 aluno faz ao modo de formulação dos contos de fada: Era uma vez e Viveram felizes para sempre. Ambas as orações, presentes no texto do aluno, constituem os contos infantis que, depois de uma lição de moral ou ensinamento, tudo termina bem. O segundo motivo é o elo que existe entre a personagem bruxa e a aparição do castelo, demonstrando que as bruxas, em contos de fada, viviam em castelos afastados do meio urbano. Ambos os motivos nos levam a crer que os contos de fada fazem parte da história de leitura desse aluno. 
Para finalizar, será exposta outra SD advinda da leitura de um dos alunos, que denomina a personagem de forma curiosa:

SD-6

Era uma vez uma bruxa chamada Clotilde. Clotilde havia encontrado um gato e chamou ele de Laranjinha.

Durante a análise desse texto, foi possível descobrir que, além de ler contos de fada, esse aluno assiste a programas de entretenimento infantil, pois Clotilde é o nome da vizinha que as crianças do cortiço do seriado Chaves apelidam de Bruxa do 71.

Para finalizar essa parte, nos últimos três casos descritos anteriormente, percebemos os textos que compõem as histórias de leituras dos alunos presentes nas suas produções textuais. Isso mostra que, quando eles não são induzidos a um gesto interpretativo conduzido pelo mediador, o professor, estes assumem a posição de autoria do seu texto, que se é fundamental para a formação de sujeitos críticos.

\section{Reescritura imagética, um espaço de incertezas}

A reescrita é normalmente explorada, nas aulas de Língua Portuguesa, como ferramenta para que o aluno alcance um melhor rendimento na escrita. Os equívocos dos alunos são corrigidos pela professora e, com isso, a produção textual se aperfeiçoa em sua organização. Apesar da semelhança na nomenclatura, para a Análise do Discurso, a reescritura tem outra finalidade, que é a de investigar o processo de interpretação do aluno a partir de um textoorigem, ou seja, analisar as (não)-coincidências (GRANTHAM, 2002, p. 194) de sentido entre a leitura dos alunos-leitores e o texto-origem (TO). Segundo Grantham (ibdem, p. 195), a reescritura é um processo de leitura em que os sujeitos-leitores deslocam sentidos já postos, mas não mudam a formação discursiva. Logo, na reescritura, para a Análise do Discurso, se deslocam alguns sentidos, se modifica o texto-origem, porém não totalmente. A seguir será exposta a SD-7 que concorda com essa defesa. 
SD-7

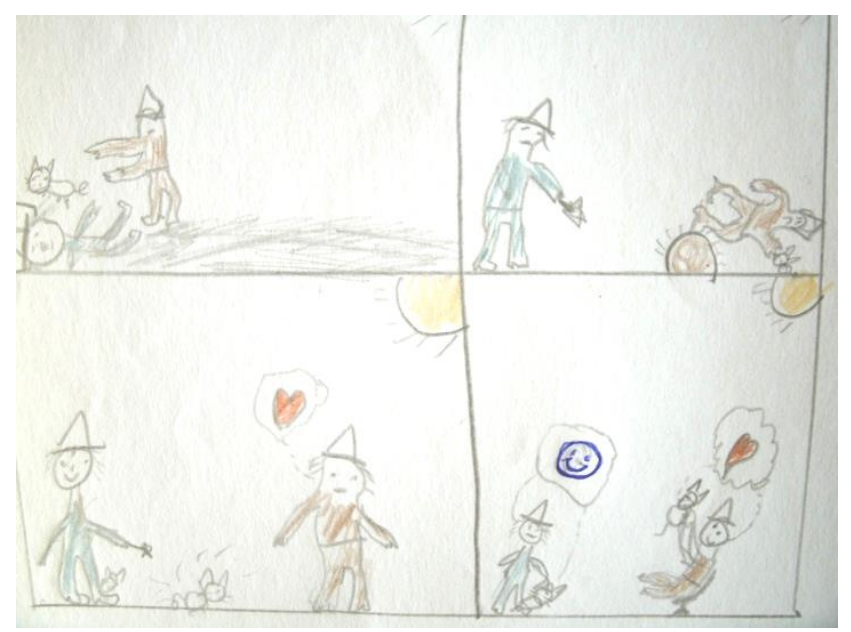

Na reescritura imagética SD-7, o aluno produz o resumo em relação ao TO, ele explicita os momentos principais do enredo, não fugindo totalmente ao discurso do autor. No momento final da reescritura, na última imagem, a SD-7 coloca em dois balões os sentimentos dos personagens. A bruxa está feliz, representada pelo smile (rosto sorridente). No texto-origem, a bruxa não demonstra clara expressão de contentamento, apenas revela uma leve expressão de satisfação pelo que fez em virtude de presenciar o momento de afeto entre a menina e o gato. Já segundo a SD-7, a bruxa está explicitamente feliz pelo que fez. Isto comprova a assunção do aluno à autoria do texto.

A reescritura a partir da sequência de imagens Pega Ladrão de $A$ Bruxinha Atrapalhada, de Eva Furnari (1984), expôs os alunos à opacidade da imagem, às lacunas significantes do texto. A produção de sentidos, nesses casos, Grantham (2002) denomina como preenchimentos discursivos, que ocorre somente na reescritura, quando o leitor preenche com efeitos de sentido as lacunas do dizer do texto-origem. Nesse momento, em que o leitor se posiciona quanto ao dizer do autor, é que entendemos se tratar da instauração da autoria, já que ele está atribuindo um novo sentido para o texto-origem. Durante a reescritura imagética, presenciamos, nas duas sequências discursivas abaixo, essa característica: 

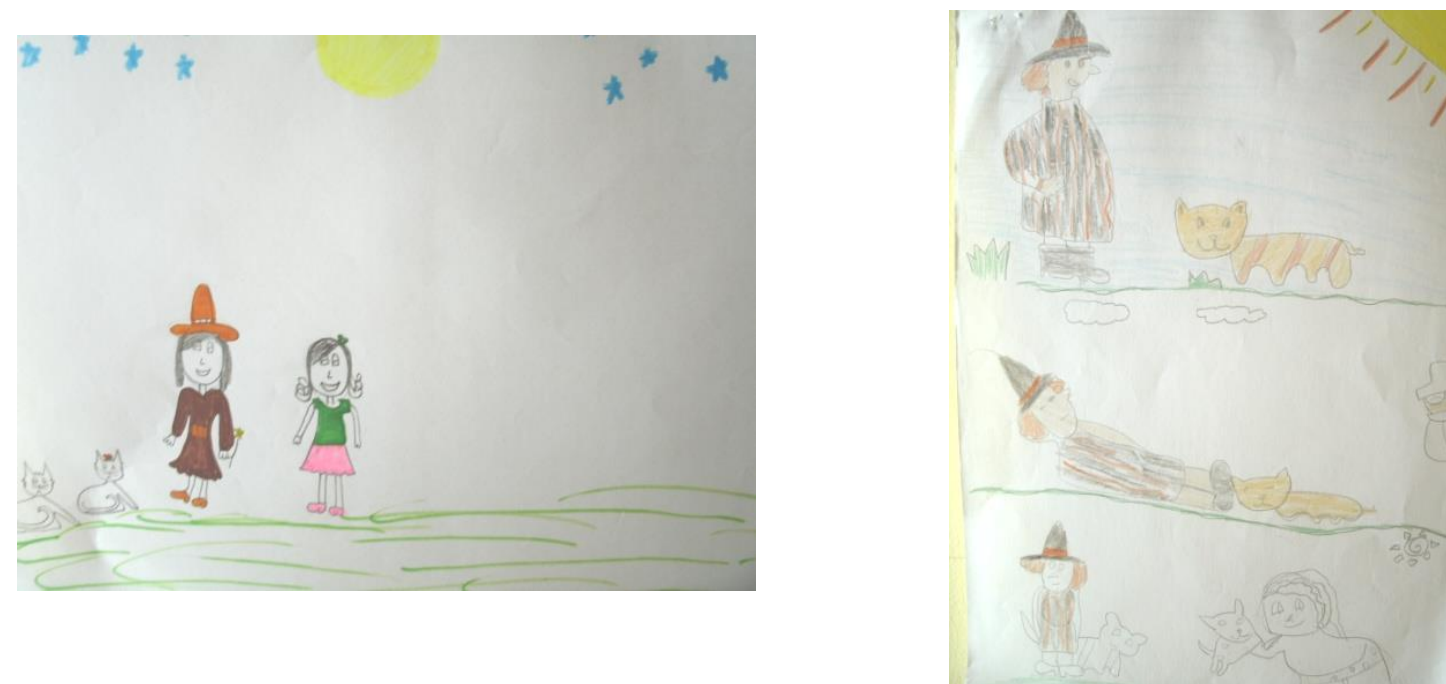

Em ambas as sequências discursivas, presenciamos uma diferença explícita. Na SD-8, o aluno reescreve a história usando a lua e as estrelas para fazer a referência tempo-espacial da narrativa, que, segundo ele, se passava à noite. Na SD-10 encontramos a presença do sol e de algumas nuvens, situando temporalmente um fato diurno. $O$ curioso é que o texto-origem permite esse preenchimento discursivo quanto ao turno da narrativa, porque não explicita nada que localize o leitor no tempo e também no espaço onde passa a história.

Quanto à presença das histórias de leitura na reescritura dos alunos, encontramos uma imagem bastante interessante na SD-10, que nos permite comparar a outra imagem de um programa de televisão.

SD-10
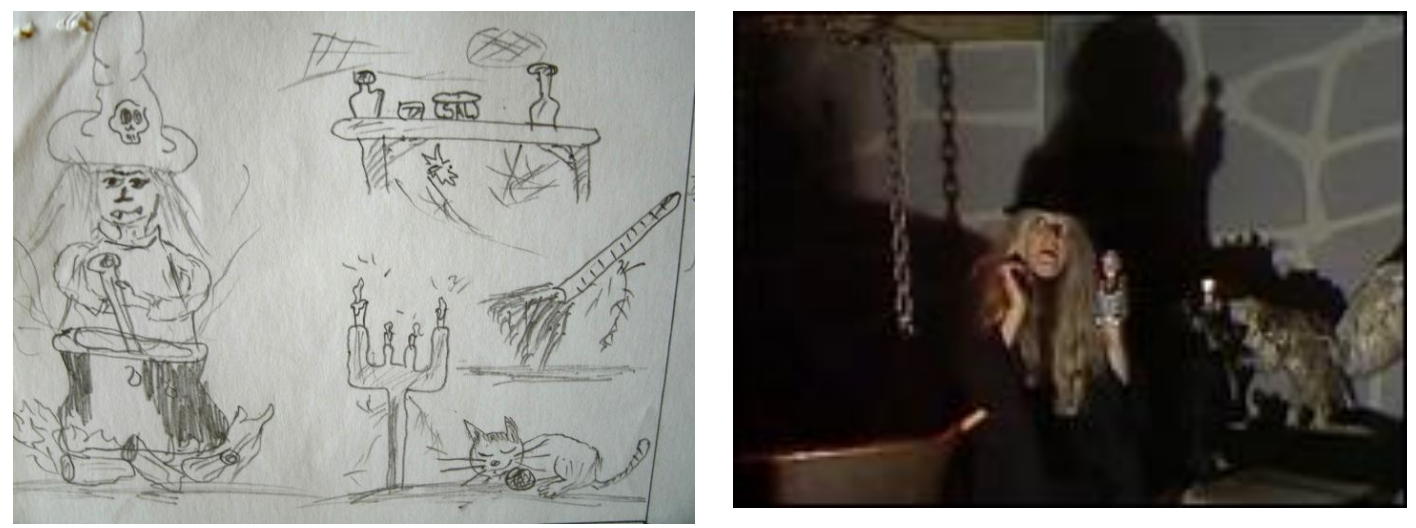

(Legenda: Casa da Dona Clotilde, imagem do seriado retirada de: <http://www.viladochaves.com/cenarios.htm>) 
$\mathrm{Na}$ SD-10, o aluno reescreve a narrativa em apenas uma imagem, focando toda sua atenção na personagem bruxa. A despeito de todo o desencadeamento das ações que indica $O$ texto, o sujeito se deteve em significar 0 universo discursivo que conhece acerca das bruxas. A reescrita imagética da SD-10 parece remeter, precisamente, a um dos episódios do seriado Chaves, em que as crianças do cortiço ao entrarem na casa da Srta. Clotilde, vulgo Bruxa do 71, imaginam uma situação em que ela está fazendo uma bruxaria e conversa com seu gato chamado Satanás, o que sugere para as crianças que ela está interagindo com o diabo. Em ambas as imagens, percebemos a personagem bruxa, relativamente parecidas, a vestimenta, o caldeirão, onde elas fazem o feitiço, o castiçal com velas e também os elementos para a realização do feitiço. O gato e a vassoura, presentes na reescritura, não aparecem na imagem retirada da internet, mas fazem parte do episódio. Com isso, a análise nos leva a crer que o aluno assiste ao seriado Chaves e esse episódio está presente nas histórias de leitura desse aluno.

Como percebemos nas reescrituras analisadas recentemente, os leitores assumiram a posição de autores estimulados pela opacidade do texto imagético e produziram um efeito de singularidade nas reescrituras. Mesmo não indo de encontro ao que foi dito pelo autor no TO, conseguiram modificar o texto, imprimindo um sentido original. Esses gestos interpretativos entre o TO e a reescritura é que permitem ao aluno essa apropriação do seu dizer.

\section{Considerações finais}

A realização do trabalho em uma $7^{\text {a }}$ série do ensino fundamental para a coleta dos dados que embasam essa pesquisa, a revisão teórica e as análises feitas propiciaram a compreensão acerca das interpretações dos alunos sobre a sequência imagética, assim como outros conhecimentos sobre o ensino de Língua Portuguesa no sistema escolar, mais precisamente relativos ao uso de texto em sala de aula.

Embora o texto seja bastante explorado nas aulas de Língua Portuguesa, cabe salientar que a única materialidade textual escolhida é a verbal. Isso nos aclara que o texto é usado com finalidades didáticas. Há ainda outro problema, 
quanto à exclusividade do uso do texto verbal pela escola: se os alunos não mantiverem contato com outras materialidades significantes, como a imagem, que Ihes induz a realizarem a interpretação, de que maneira propiciarão a formação de cidadãos críticos se não ensiná-los a refletir e interpretar? É dever da escola estimular o aluno a interpretar autonomamente, sem a intervenção do professor. Daí a importância do professor estar consciente que o discurso didático não pode prejudicar a iniciativa dos alunos.

A leitura do texto imagético provocou diversas possibilidades de interpretações, como já defendidas pela Análise do Discurso. Essa polissemia também se deve ao fato de que os alunos não foram induzidos a nenhuma prévia interpretação, somente thes foram solicitadas as tarefas a partir do texto imagético. O que comprova a relevância do uso do texto imagético na sala de aula como motivador à assunção da autoria por parte do sujeito-aluno.

Quanto às análises das reescrituras imagéticas dos alunos, fez-se outro desafio, o de não apenas interpretar, mas compreender, como defende Orlandi (2012, p. 19) o processo interpretativo dos alunos. De acordo com a análise das reescrituras imagéticas na parte III, conseguimos perceber que alguns alunos, assim como previsto por Pêcheux (1988), deslocaram os sentidos postos pelo texto-origem, preenchendo as lacunas do texto imagético, não o anulando, mesmo quando o desvio foi mais intenso. Isso mostra que a reescritura também é espaço de produção de sentidos e, assim, de instauração da autoria, como observa Grantham (2002).

Para finalizar, podemos concluir que os textos imagéticos estimulam os alunos à apropriação do seu dizer, ou ainda, podemos dizer que os induz a interpretação pelo fato de estar exposto à opacidade da imagem, que não permite que os sentidos apareçam como evidentes. As lacunas deixadas pela imagem é que levam o aluno a assumir tal posição. Com isso, cabe salientar a importância do uso de materialidades significantes, sobretudo a imagem, no contexto escolar. Essas materialidades acabam por incitar os alunos a criar efeitos de sentido singulares e, assim, desenvolver a capacidade interpretativa, necessária no cotidiano dos sujeitos críticos e reflexivos. É cabível à escola o primar por esta formação. 


\section{Referências bibliográficas}

ASSOLINI, Filomena Elaine P. O discurso pedagógico escolar: condições de produção, interpretação e a emergência da autoria. In: TFOUNI, Leda V. Múltiplas faces da autoria. ljuí: Ed. Unijuí, 2008.

CHARTIER, Roger. A aventura do livro: do leitor ao navegador. São Paulo: Ed. UNESP, 2009.

CORACINI, Maria José. Leitura: Decodificação, processo discursivo...? In: CORACINI, Maria José. 0 jogo do discurso na aula de leitura. Língua Materna e Língua Estrangeira. 3를 edição: Campinas, SP, Editora Pontes, 2010.

FERNANDES, Carolina. $O$ uso da imagem no ensino de leitura e escrita: propostas de atividades e avaliação In: IRALA, Valesca B.; SILVA, Silvana (orgs). Ensino na área da linguagem: perspectivas a partir da formação continuada.1 ed. Campinas: Mercado de Letras, 2012, v.1, p. 15-30.

FURNARI, Eva. A bruxinha atrapalhada. 2 Ed. São Paulo, SP: Global Editora, 1984.

GRANTHAM, Marilei Resmini. Da releitura à escritura: Um estudo pelo viés da pontuação. Editora RG: Campinas, 2009.

LAGAZZI-RODRIGUES, Suzy. Texto e autoria. In: ORLANDI, ENI P. Introdução às ciências da linguagem: Discurso e textualidade. $2^{\mathrm{a}}$ Edição. Campinas, SP: Pontes Editores, 2002.

LEANDRO-FERREIRA, Maria Cristina et al. Glossário de termos do discurso. Porto Alegre: UFRGS. Instituto de Letras, 2005.

MARTINS, Wilson. A palavra escrita: história do livro, da imprensa e da biblioteca. São Paulo: Editora Anhembi limitada, 1957.

ORLANDI, Eni P. Análise de discurso: princípios e procedimentos. 4 Ed. Campinas, SP: Pontes, 2002.

ORLANDI, Eni P. Autoria e interpretação. In: ORLANDI, Eni P. Interpretação: autoria, leitura e efeitos do trabalho simbólico. Petrópolis, RJ: Editora Vozes, 1996.

ORLANDI, Eni P. Discurso e leitura. 9 Ed. São Paulo: Cortez Editora, 2012.

ORLANDI, Eni. Discurso e texto: formulação e circulação dos sentidos. 3 Ed. Campinas, SP: Pontes, 2008. 
PARÂMETROS CURRICULARES NACIONAIS: Língua Portuguesa. Brasília, DF, v.02, 1997. Disponível em:

<http://portal.mec.gov.br/seb/arquivos/pdf/livroo2.pdf.> Acessado em: 05 de maio de 2012. 
Artigo recebido em: 13 de outubro de 2013

Artigo aprovado em: 05 de janeiro de 2014

\section{Sobre as autoras:}

Carolina Fernandes é Doutora em Letras pela Universidade Federal do Rio Grande do Sul, é professora do Curso de Letras da Universidade Federal do Pampa. Sua última publicação é: "O uso da imagem no ensino de leitura e escrita: propostas de atividades e avaliação", in: IRALA, Valesca Brasil; SILVA, Silvana (Org.). Ensino na área da linguagem: perspectivas a partir da formação continuada. 1ed. Campinas: Mercado de Letras, 2012. Outros dois capítulos de livros estão no prelo para sair pelas editoras Paulinas e Mercado de Letras.

Carla Carolina de Vargas Oliveira é graduanda do $8^{\circ}$ semestre do curso de Licenciatura em Letras- Habilitação: Português/Espanhol e Respectivas Literaturas, na Universidade Federal do Pampa. Este trabalho foi orientado pela Profa. Dra. Carolina Fernandes, durante o Trabalho de Conclusão de Curso II, e está vinculado ao Projeto de Pesquisa Escritas em deriva sob coordenação dessa mesma professora. 